\title{
l. El tiempo libre de los trabajadores en la norpatagonia. De la cultura política, las prácticas recreativas y deportivas al discipli- namiento social 1900-1945
}

Enrique Mases $^{1}$

\section{Introducción}

Si el mundo del trabajo, desde el inicio mismo de la formación de la clase obrera, fue objeto de diversas preocupaciones y acciones por parte del Estado, la Iglesia, las organizaciones políticas, los sindicatos y el tiempo libre de estos mismos trabajadores no le fue en zaga y por diferentes motivos, a medida que avanzaba el periodo estudiado y los trabajadores accedían a una cuota mayor de tiempo dedicado al ocio, más significativa era la preocupación de éstos por incidir en su conformación y consumo.

En efecto, a principios de siglo XX en nuestro país, la jornada laboral en el ámbito urbano tendió a disminuir, como efecto de un conjunto de circunstancias, algunas asociables a modificaciones económicas básicas y otras vinculadas a la lucha por el logro de reivindicaciones sociales, como la reducción de la jornada de trabajo a ocho horas o el descanso semanal. En la obtención de estas mejoras, los trabajadores y sus organizaciones gremiales se vieron acompañados en más de una ocasión por otras organizaciones políticas e incluso por la propia Iglesia Católica, como sucedió con el descanso dominical, donde paradójicamente aparecen circunstancialmente unidos en pos de esta reivindicación a actores que eran irreductibles adversarios ideológicos en el tema de la cuestión obrera.

En la lucha por el descanso semanal, quienes se movilizaban por su logro desde el campo sindical, es decir, anarquistas y socialistas, encontraron un aliado inesperado en la Iglesia, que también bregaba por la necesidad

1- Grupo de Estudios de Historia Social (GEHiSo), Universidad Nacional del Comahue. E-mail: emases@jetband.com.ar. 
del descanso dominical para los trabajadores. Así, en los albores del siglo $X X$, se ve a los integrantes de los Círculos de Obreros Católicos participar de manera intensa en la movilización a favor de esta reivindicación, lo mismo que a los legisladores católicos en el debate que se plantea en el congreso Nacional. Claro que esta coincidencia, puramente circunstancial, se planteaba desde argumentaciones totalmente opuestas entre sí, porque mientras los representantes católicos en el Congreso insistían en el hecho que el día de reposo debía ser necesariamente el domingo, planteando la necesidad de la unidad familiar, el diputado socialista Palacios y otros dirigentes partidarios y gremiales preferían hablar de descanso hebdomadario, basando sus razones en el aspecto fisiológico de la necesidad de un día de descanso semanal para el trabajador. ${ }^{2}$

Pero más allá de esta coincidencia circunstancial, debemos señalar que la ampliación de los momentos de ocio de los trabajadores fue un objetivo que se disputaron por igual organizaciones políticas y sindicales, con sus diferentes representaciones ideológicas, así como la Iglesia y el propio Estado, no sólo en el ámbito de la ciudad de Buenos Aires o de las grandes ciudades del litoral, sino que ésto también se reprodujo en el escenario de la norpatagonia, aunque con ciertas peculiaridades propias del ámbito regional.

En efecto, desde muy temprano el mundo de los trabajadores urbanos de la región se fue configurando de acuerdo con tres rasgos principales: eran recién llegados, estaban en plena inserción social y necesitaban por lo tanto de instituciones que sirvieran a ese fin.

Como señala González Leandri para el caso de la ciudad de Buenos Aires, también en este ámbito, aunque más temprano en el tiempo y más marcado en Neuquén que en Río Negro, "las sociedades que allí surgieron fueron por lo tanto sociedades en construcción, casi de frontera, donde las perentorias necesidades de los primitivos habitantes impulsaron a un tipo peculiar de acción colectiva. Esta situación, en la que se vio inmersa una parte importante de los sectores populares urbanos, está por lo tanto en el origen mismo de otra de las características de la cultura popular de los años treinta, así como del completo período de entreguerras; su marcada inquietud asociativa" (González Leandri 2001, 219). Para el caso que nos ocupa, las asociaciones mutuales, los clubes deportivos, las parroquias con sus círculos

2- Cámara de Diputados. Diario de Sesiones, Año 1905.

.74 . 
de obreros y los centros socialistas, entre otras instituciones, operaron como centros constructores de sociabilidad en un ámbito donde las identidades iban tomando forma y dando contenido a esa forma en el diario devenir.

Al mismo tiempo, estos núcleos urbanos muestran otra importante característica, y es la escasa diferenciación social, tanto en el terreno espacial como en el de la sociabilidad, ya que los habitantes de estos centros urbanos permanecen unos cerca de otros, sin una precisa delimitación de clases; el signo distintivo es su composición social marcadamente heterogénea. Allí se relacionan y conforman redes sociales que articulan a diferentes tipos de trabajadores en relación de dependencia con profesionales, pequeños comerciantes, funcionarios estatales, y también trabajadores desocupados y marginales. Recién al final del período podemos desagregar espacialmente en algunas ciudades un centro de los barrios.

Finalmente, digamos que tampoco el mundo urbano territoriano equivale al mundo industrial de las grandes ciudades de Inglaterra del siglo XIX, con sus innumerables fábricas y sus arrabales abarrotados de obreros que conforman particulares formas de sociabilidad y de identidad cultural, tan bien descriptos en los trabajos de E. Hobsbawm (1991) o G. Stedman Jones (1987). No hay un conglomerado fabril en cada una de las ciudades que pueblan la región y las actividades calificadas y no calificadas aparecen entremezcladas en una amplia gama de actividades que van desde las que tienen que ver con el transporte ferroviario, los empleados de comercio, la docencia, las agroindustrias, de pequeños y medianos talleres, en la construcción, hasta los trabajos ocasionales llevados a cabos por trabajadores sin calificación.

En realidad, en dónde si hay una importante concentración de obreros, es en algunas puntuales actividades encaradas por el Estado, como la construcción de obras hidráulicas, líneas férreas o la actividad petrolífera, pero allí la cultura de los trabajadores y sus formas de sociabilidad no se expresan libremente sino que están fuertemente condicionadas y subordinadas por el propio Estado, tal cual lo veremos más adelante.

Es entonces en este particular ámbito urbano, donde los trabajadores desarrollaron distintas formas de sociabilidad y consumo del tiempo libre, las que se expresaron en varios escenarios posibles. Dichos ámbitos podían ser de carácter informal, como el de la calle y las relaciones de vecindad, el taller y las solidaridades derivadas del trabajo, el café y bar, el cinematógrafo o las fiestas populares; o bien institucionalizados, como las asociaciones artísticas, los clubes deportivos, las bibliotecas populares. También, se desa- 
rrollaron en las asociaciones mutuales de carácter étnico, los sindicatos, los círculos de obreros o los centros socialistas entre otros.

En este marco, el acortamiento de la jornada de trabajo dio nuevas posibilidades de vida en familia y respecto al uso del tiempo libre y se prefiguró un escenario territoriano particular donde los militantes político sindicales, miembros de la iglesia católica y funcionarios estatales, pugnaron por igual por incidir en la conformación y ocupación del tiempo libre de los trabajadores de la región.

A partir de estas consideraciones previas, el presente trabajo se propone analizar de qué manera el tiempo libre de los trabajadores norpatagónicos fue objeto de atención y eventualmente de acciones de parte de las organizaciones gremiales y políticas; la iglesia y aún el propio Estado, en el período que va desde fines del siglo XIX hasta el advenimiento del peronismo.

Para ello, indagaremos en las diferentes estrategias que cada una de estas instituciones llevan adelante, no sólo para planificar la recreación, los deportes y el mundo cultural de los trabajadores, sino también para propagandizar sus idearios en el caso de las organizaciones gremiales y políticas, de cristianizar y a la vez de disciplinar en el caso de la iglesia católica, y para controlar y también disciplinar en el caso del Estado.

En este último caso, intentaremos avanzar en el estudio de la relación entre Estado y tiempo libre de los trabajadores, más allá del rol que el primero tiene como regulador de las actividades de la sociedad; es decir más allá del control que ejerce por un lado de las fiestas, diversiones, pasatiempos, etc., y por otro lado, de la reglamentación de los mismos. En realidad nos interesa analizar el protagonismo del Estado en la propia relación con los trabajadores bajo su dependencia, y que se expresa, en el caso del espacio norpatagónico, en las concentraciones obreras de las grandes obras estatales.

\section{Las Organizaciones Gremiales y Políticas}

Tanto las organizaciones gremiales como aquellas políticas que intentaron representar los intereses de los trabajadores, especialmente los socialistas, trataron de incidir activamente en el tiempo libre de los trabajadores. Desde la acción educativa y cultural, pasando por la organización de actividades recreativas hasta incursionar en el deporte, básicamente el fútbol, todas estas acciones forman parte de una estrategia dirigida a educar, afianzar la cultura política e incluso, fortalecer la organización gremial.

.76 . 
En este sentido, debemos señalar que la actividad sindical en la Argentina finisecular tenía como característica principal su intermitencia, ya que las sociedades de resistencia, fuera del pequeño núcleo de activistas, salvo en los períodos de conflictos, no constituían un ámbito de atracción para los trabajadores. Por lo tanto, uno de los objetivos prioritarios de sus conducciones era lograr desarrollar formas de participación obrera en el seno de esas organizaciones. Uno de esos métodos fue la realización de actividades recreativas y sociales. Así, bajo la tutela del sindicato se organizaban bailes en los propios locales gremiales o en otros ocupados al efecto, intentando con esta actividad atraer a los obreros más remisos y ampliar el marco propagandístico. En realidad, estas acciones eran llevadas adelante principalmente por los sindicatos de orientación socialista, ya que los sectores anarquistas se oponían vivamente con el argumento de que las Sociedades de Resistencia eran órganos de lucha y no de fiesta. ${ }^{3}$

En cambio, para los anarquistas su estrategia se basaba en la gran velada- conferencia que generalmente se desarrollaba los fines de semana, para cumplir con el triple objetivo de propagandizar, educar y entretener, aunque cuando la ocasión lo permitía se la hacía coincidir con las recordaciones de las fechas patrias, como una especie de contraofensiva ideológica cultural a las conmemoraciones organizadas por el sistema educativo nacional. Al respecto señala Dora Barrancos "En ocasiones como el 25 de mayo o el 9 de julio, había una amplia oferta alternativa de festejos libertarios. La gran velada-conferencia incluía, a veces, hasta dos pequeñas obras teatrales, y/o varias declamaciones seguidas siempre por lo menos de dos participantes, oradores 'de fondo'. Los números variaban pero en general se contaban no menos de siete, lo que permite suponer que la duración de estos encuentros se aproximaba a las tres horas. Obviamente un papel central era cumplido por la presencia del orfeón que al final acompañaba el 'baile familiar' con que solían culminar las funciones realizadas durante el fin de semana" (Barrancos 1990: 309).

Pero además de cumplir, como señalamos anteriormente, con los ob-

3- A propósito de esta controversia una publicación anarquista La Organización Obrera en un artículo titulado "Sociedades de Recreación y sociedades de Resistencia" criticaba fuertemente a la primera porque: "tienen como objeto final y único el divertimento mutuo, el que sirve de base para fomentar el espíritu fantoche gratuito en esos carnavales que todos los años se realizan”, en: La Organización Obrera. 25 de agosto de 1904 (Citado en Falcón 1986). 
jetivos de divertir, educar y difundir el ideal libertario; la organización de estas grandes veladas desempeñaban un rol significativo en la orientación del tiempo libre, pues como sostiene Juan Suriano "Ios anarquistas intentaban influenciar a los trabajadores para que no concurrieran a esos lugares considerados poco edificantes como el bar, el café, los prostíbulos, los cabarets, las fiestas de carnaval y otros ámbitos considerados indeseables y proclives a empujar a los individuos a la mala vida y el alcoholismo" (Suriano 2001: 147).

Estas veladas-conferencias tienen gran impulso hasta mediados de la década del veinte cuando van a dejar su lugar central a la función teatral donde se destacan diferentes grupos filo dramáticos, tal el caso de la agrupación "Arte y Natura".

Junto a estas, otra forma de entretenimiento utilizada por los militantes anarquistas, era el picnic, donde los educadores libertarios reunían esparcimiento y educación además de propagandizar en el terreno el naturismo que contaba, por esos años, con la aceptación de muchos libertarios (Barrancos 1990:310).

Si el desacuerdo era manifiesto entre anarquistas y socialista en el carácter de las actividades recreativas y sociales que debían llevar adelante las sociedades de resistencia, en cambio el acuerdo era total, no sólo entre ellos sino también entre sindicalistas y posteriormente comunistas, en la importancia que todos le adjudicaban a la actividad relacionada con las bibliotecas. Sin distinción de ideologías, la biblioteca aparecía como una extensión natural del sindicato y la fundación de una nueva organización gremial, era siempre acompañada por la creación de una biblioteca anexa. ${ }^{4}$ Sin embargo, como acertadamente señala Ricardo Falcón, esas bibliotecas por su composición, en cuanto a los títulos que albergaban e intención eminentemente formativa, que suponían lecturas previas, no podían interesar más que a un sector de obreros bien determinados; es decir, a aquéllos que tuvieran cierta práctica política (Falcón 1986: 91).

Este particular carácter de las bibliotecas se repetía en otras actividades culturales, como las conferencias que también convocaban a un público avisado y con cierta formación política.

4- "Empleados de Comercio General Roca (Río Negro) con fecha 27 del mes pasado, se fundó un centro de empleados de comercio en esta localidad. (...) Los fines que aspira el mencionado centro son estrechar los lazos de compañerismo, la unión del gremio y la formación de una biblioteca para los socios.”, en: Periódico Río Negro General Roca, Año XI N 5526 de junio de 1022. p. 4, col. 1 y 2.

.78 . 
Finalmente, una tercera acción tendiente a incursionar en el tiempo libre de los trabajadores es la que se relaciona con las prácticas deportivas, particularmente y en forma determinante con el fútbol, en donde militantes socialistas primero, y comunistas después, tienen una activa participación. Al respecto, el dirigente comunista Pedro Chiarante señalaba: "Muchos desconocen que los grandes clubes de fútbol fueron fundados por jóvenes trabajadores, algunos militantes del Partido Socialista, o por sus amigos ganados por esas ideas, y también por anarquistas que luego se afiliaron al Partido Comunista. Lo mismo sucedió con las bibliotecas populares, o clubes culturales. Argentinos Juniors, por ejemplo, es el resultado de la fusión de dos clubes muy modestos de La Paternal, que se Ilamaban Mártires de Chicago y $1^{\circ}$ de Mayo. Sus nombres son bastante claros (...). De la misma manera, el núcleo fundador de Huracán estaba influido por jóvenes que tenían ideas socialistas y anarquistas" (Chiaranti 1976: 26-27).

Esta última expresión de Chiaranti es una verdadera rareza, ya que el pensamiento libertario era profundamente crítico de las prácticas deportivas, especialmente en el fútbol y el boxeo, a los que consideraban "placeres viciosos". En este sentido, abundan los comentarios críticos en La Protesta, como el vertido por un grupo de militantes ácratas del Ateneo Parque Patricios, quienes dirigiéndose "no a los que no nos conocen ni comprenden (...) pues creen que sus puestos están en las canchas de football y otros en las tabernas gastando el mismo jornal que ganan, antes de concurrir a una biblioteca a leer un libro"s.

Mucho más explícita resulta la participación del Partido Comunista en la organización de la práctica del fútbol entre los obreros, cuando en 1924, a partir de una iniciativa de la Federación Juvenil Comunista, se crea la Federación Deportiva Obrera, que llegó a nuclear en sus seis años de trayectoria a más de setenta clubes obreros a nivel nacional, y movilizó a su alrededor una importante cantidad de jóvenes, a quienes intentaba guiar en una nueva práctica deportiva diferente y opuesta a la burguesa (Mateu 1998: 67).

Sin embargo, esta iniciativa de los militantes comunistas es objeto de severas críticas no ya desde el anarquismo, sino desde el sindicalismo revolucionarios y quedan expresadas en el periódico Bandera Proletaria, órgano oficial de la Unión Sindical Argentina, una de las centrales obreras que nucleó al proletariado argentino entre 1922 y 1930 y difusor del bagaje teórico

5- Periódico La Protesta del 3 de enero de 1924 (en Barrancos 1990: 312).

- Instituto de Estudios Socio-Históricos - Facultad de Ciencias Humanas - Universidad Nacional de La Pampa - 
de la corriente sindicalista, de fuerte presencia en el movimiento obrero en las primeras décadas del siglo XX.

En este periódico, en un artículo aparecido en 1926 y titulado El deporte obrero se sostenía que "El llamado deporte obrero es uno de los tantos recursos para atraer diversiones (a la clase obrera) que la seducen y poder catequizarlas para el propio partido. Nosotros creemos que esa dedicación es perniciosa para el movimiento obrero, porque sustrae y desvía energías e inteligencias. Si de los veinticinco clubes de football "obrero" existentes en la actualidad se formara un sólo Ateneo revolucionario, se haría más para la emancipación humana que con todos los partidos de pelota juntos.

Los revolucionarios deben enseñar otra cosa a la juventud que dar patadas -o coces- a una pelota. Ahí están los libros, los folletos, la necesidad de cultura y educación, de capacitación intelectual y moral. Esto es lo que urge en nuestro movimiento. El deporte servirá para alargar los pies o robustecer los puños, pero jamás hará más grande la inteligencia, ni más bueno los corazones"

En cuanto al escenario regional, debemos señalar que, si bien en el período estudiado aparece cierta militancia anarquista, (particularmente en Río Negro), sindicalista y más tarde comunista, sin lugar a dudas es el socialismo quien tiene un papel preponderante en la organización gremial de los trabajadores en la norpatagonia y su articulación política. De la misma manera, serán sus dirigentes y militantes quienes se preocupen por el tiempo libre de los trabajadores, intentando para ello desarrollar una serie de actividades que se relacionan fundamentalmente con la educación y la cultura.

En efecto, desde muy temprano el socialismo se hace presente en el norte de la patagonia, pero no con la creación de sindicatos, sí con la conformación, en 1919 de un centro obrero con biblioteca anexa en la ciudad de General Roca y uno de similar características en la ciudad de Neuquen. Según sus inspiradores, el ubicado en territorio rionegrino tenía como principal objetivo "el mejoramiento moral, material e intelectual del proletariado de la región". Para ello el centro se convertiría en un ámbito propicio para que los trabajadores cambiaran impresiones y pudieran "recurrir a la biblioteca en demanda de alimento espiritual, tan escaso en la región". ${ }^{7}$

El Centro Obrero de Neuquén, dirigido por pequeños comerciantes,

6- Periódico Bandera Proletaria, Año V No 279. 14 de agosto de 1926, p. 1.

7- Periódico Río Negro, № 391 General Roca, 1/05/1919 p. 6 col. 1 y N³93 15/05/1919, p. 4 col. 4.

.80 . 
empleados y profesionales, alcanzó a los pocos meses de su fundación los 150 afiliados. Entre sus objetivos, se señalan fomentar la "liberación mental y económica de los trabajadores, ayudar a los obreros en lucha con las empresas capitalistas, intervenir en las cuestiones agrarias, participar en las contiendas políticas municipales y difundir la cultura en todas sus manifestaciones en el seno de las masas trabajadoras" (Mases 1994: 97-98).

Estos centros obreros compartían las características que Luis A. Romero atribuye a los Centros Socialistas de Buenos Aires: la pretensión simultánea de ganar votos y educar tanto a los votantes reales como a los potenciales votantes extranjeros, la presencia en su seno de bibliotecas, grupos teatrales, clases de capacitación y ámbitos recreativos. Se trataba de grupos reducidos, con cierta tendencia al elitismo y al sectarismo, pues se consideraba más importante la calidad moral de sus miembros que su mero número. La actividad tendía a desbordar lo político para proyectarse en lo social, invadiendo esferas de influencia de grupos de existencia previa y politizando actividades que anteriormente se habían mantenido al margen de las actividades partidarias (Romero 1995: 114).

En la práctica, la actividad respecto al tiempo libre se canalizaba tanto en la faz educativa, con el dictado de clases nocturnas de lectura y escritura para adultos, como cultural. Junto a la presencia del cuadro filo dramático y la biblioteca, aparece como una actividad destacada la organización de conferencias sobre temas muy variados que iban desde política petrolera a problemas agrarios y desde educación a la problemática de la emancipación femenina.

Además, el Centro Obrero de Neuquén contaba con un órgano de difusión: el periódico Unión que contenía tanto artículos doctrinarios como campañas de índole moralizante contra el juego, así como críticas y comentarios literarios. El objetivo declarado de llevar la ilustración a los trabajadores se evidencia en una toma de posición acerca de la educación como foco de irradiación del progreso.

A fines de 1919, ambos centros modifican su denominación por la de Centro Socialista, adhiriendo al partido del mismo nombre y continuando con su actividad educativa y cultural.

En el ámbito sindical, a principios de la década del veinte hace su aparición la Sociedad Gremial de Maestros más conocida como Asociación de Maestros, con sede en General Roca y con alcance regional cuyos objetivos eran: "fomentar la integridad moral de sus componentes, la mayor 
preparación general y especial de los mismos, al par que su mejoramiento material"8.

Presidida por Edmundo Gelonch, conspicuo miembro del Partido Socialista primero y luego del Partido Socialista Independiente, la asociación compartió los rasgos más clásicos del sindicalismo socialista en cuanto al aprovechamiento del tiempo libre de sus afiliados. La conformación de una biblioteca, de un cuadro filo dramático que representaba obras de contenido social y el dictado de conferencias públicas sobre temáticas tanto sociales y sanitarias como de índole histórica fueron algunas de las acciones desarrolladas. La actividad de esta asociación fue bastante intensa y las veladas culturales que organizaba contenían un vasto programa, que incluía desde conferencias e intermedios musicales hasta la puesta en escena de diferentes obras teatrales. Las mismas contaban con una amplia convocatoria de público que iba más allá de los propios afiliados tal cual lo atestiguan las noticias periodísticas de la época:

"El domingo llevose a cabo la anunciada velada teatral a beneficio de la Asociación de Maestros de Río Negro y Neuquen.

El teatro de la Sociedad Española de Socorros Mutuos, donde tuvo lugar la velada, estaba al iniciarse esta, Ilena de público deseoso, como siempre, de dar aliento con su presencia a toda obra bien inspirada y de estimular las actividades espirituales de nuestra juventud.

Inició el acto, con una conferencia el director de la escuela $N^{\circ} 51$, señor Enrique Garro, versando el tema de ella sobre la vida y obra de San Martín y Bolívar, haciendo un paralelo entre estas dos grandes figuras de la emancipación americana. (...)

(...) Momentos después diose comienzo al drama "Barranca Abajo". Interpretaron esta obra un grupo de señoritas y caballeros de nuestra localidad, y se impone decir, en honor a la verdad, que se condujeron brillantemente dentro de lo que es permitido exigir del "diletantismo teatral". En el primer entreacto las señoritas Cora y Haydee Netto, cantaron algunos aires criollos, acompañados de piano por el profesor señor José Cilento.

Los intermedios musicales estuvieron a cargo del Sr. Cilento. Un galardón más para el director de escena Sr. Antonio Castano y nuestras felicitaciones al presidente de la Asociación de Maestros Edmundo Gelonch, por el éxito obtenido" ${ }^{\prime \prime}$.

8- Periódico Río Negro, General Roca, 18 de agosto de 1921, p. 4.

9- Periódico Río Negro, General Roca Año XI N 563, 22 de agosto de 1922, p. 4 col. 1 y 2.

.82 . 
Ya en la década del treinta, un nuevo elemento es incorporado por las organizaciones políticas y gremiales de la región, para ser utilizado en el tiempo libre y es el cinematógrafo, a través del cual se proyectaban películas que reflejaban en su trama un claro sesgo ideológico. Estas cumplían el doble rol, por un lado de entretener al auditorio y a la vez ser un vehículo eficaz para esclarecer políticamente a los trabajadores - espectadores en una serie de temas de actualidad algunos de alcance mundial como las disputas suscitadas por la guerra civil española primero y por la segunda guerra mundial después.

Un ejemplo que ilustra lo antedicho es el siguiente programa, que el Sindicato Único de Obreros de la Construcción de Bariloche confeccionó y llevó a cabo con motivo de la conmemoración del $1^{\circ}$ de Mayo de 1939:

\section{Programa}

$1^{\circ}$ - Himno Nacional Argentino.

$2^{\circ}$ - Cuadro simbólico "El Trabajo" y música del canto obrero "La Internacional"

$3^{\circ}$ - Las cuatro primeras partes de la soberbia producción sonora y musicada, titulada: "Tierra de España"

Visiones espléndidas de los bombardeos aéreos y batallas de Jarama y Guadalajara. Notables escenas de la lucha del heroico pueblo español por su libertada. Un bello Romance en que, el dolor pone las lágrimas en los ojos de los espectadores.

$4^{\circ}$ - Intervalo. Discurso "Mensaje a la Mujer Obrera", por la señorita ANITA DANIS.

$5^{\circ}{ }^{\circ}$ "Por tus hombres, Patria", versos por el niño R. MARTINEZ

$6^{\circ}$ - Palabras alusivas al $1^{\circ}$ de Mayo. Por la señorita O. AGUILAR

$7^{\circ}$ - Conferencia sobre el origen y alcance del Día del Trabajo, por el Secretario de la Comisión, Leoncio León Castro

$8^{\circ}$-Continuación de la película "Tierra de España".

$9^{\circ}$-Marcha final. Himno francés "La Marsellesa" 10

En cuanto a los aspectos deportivos, más allá de que el juego de paleta aparece como una de los deportes más difundido en todo este periodo, sin

10- Archivo Histórico de la Provincia de Río Negro. Ministerio del Interior. Gobernación de Río Negro, Expediente $\mathrm{N}^{\circ} 3730$ Letra S., 25 de abril de 1939. 
lugar a duda el fútbol es quien paulatinamente va concitando la atención de la mayoría de los jóvenes trabajadores.

Como símbolos de identidad colectiva, los equipos de fútbol parecen haber obrado, en un principio, en la región, como representantes de las ciudades, al punto que en ocasión de disputarse un partido entre el Athletic Club Neuquen y el Club General Roca en 1915:

“(....) Los vecinos más caracterizados se anotaron con sumas importantes en las listas de suscripción para sufragar los gastos de estadía y viaje de los huéspedes (...) ${ }^{11}$."

Sin embargo, la creciente popularización del fútbol y el surgimiento de nuevas entidades deportivas modificará el sistema de lealtades, oposiciones e identificaciones. En el caso de la ciudad de Neuquen los dos clubes más importantes eran percibidos como ámbitos propios de sectores sociales diferenciados. Según un dirigente socialista de actuación en este periodo "estos (los clubes) estaban divididos en clases sociales en ese aspecto. El club Pacífico era por lo general dirigido por los ferroviarios, entraban los del correo y los ferroviarios (...). El Club Independiente eran los empleados bancarios, los de la Cobernación, los jefes, los maestros, toda esa gente que tenía otra figuración social distinta." 12

Aún si la división real entre los socios de cada club no fuera tan marcada, como lo señala este testimonio, la sólo percepción de uno de ellos como propio y del otro como ajeno nos habla de forma de identificación colectiva de los trabajadores, que exceden los marcos de las instituciones tradicionalmente considerada parte del mundo del trabajo.

Volviendo a la adscripción de los sectores populares al fútbol, podemos señalar que ya desde la segunda mitad de la década del diez, se va consolidando la apropiación por parte de los trabajadores de la región de prácticas que anteriormente les eran ajenas. Al respecto, resulta ilustrativo el comentario del periódico La Nueva Era, que muestra su satisfacción a propósito del "movimiento de reorganización operado por la juventud patagonense en el sentido de adoptar el foot-ball como juego habitual para el desarrollo de la cultura física y entretenimientos de los ocios dominicales."

Pero además, el comentario va más allá de lo puramente deportivo, al plantear que esta iniciativa adoptada por los jóvenes deportistas de la comar-

11- Periódico Neuquén, Año VIII N 845, sábado 4 de diciembre de 1915, p. 1.

12- Entrevista al Sr. Bernardo Rousillón.

.84 . 
ca además de "consagrar las horas del descanso hebdomadario a distracciones honestas y viriles, han de producir muy pronto un cambio favorable en las costumbres, alejándola de las pasiones deplorables que actualmente la arrastran al vicio y la corrupción". ${ }^{13}$

Este último comentario resulta curioso y revelador de un pensamiento que aparece opuesto a la visión planteada por los militantes anarquistas y sindicalistas que, como hemos señalado anteriormente, veían al fútbol como un placer vicioso que embrutecía a las masas obreras. Por el contrario, La Nueva Era no sólo alienta esta práctica deportiva sino que además le asigna un rol importante en la elevación moral de los jóvenes territorianos.

\section{La Iglesia}

Enmarcado en el protagonismo que el movimiento social cristiano intenta desarrollar, como forma de terciar en el creciente conflicto social que desde fines del siglo pasado enfrentaba a la elite gobernante por un lado y a las representaciones ideológicas y políticas de los trabajadores por el otro, hacen su aparición a la década de 1880 los Círculos de Obreros Católicos. Apuntaban a cumplimentar dos objetivos principales: la difusión y defensa de los principios católicos entre los trabajadores y contrarrestar la creciente influencia del socialismo y el anarquismo en el movimiento obrero.

La difusión de la encíclica Rerum Novarum de León XII, aparecida en 1891, con su llamamiento a los católicos del mundo, a prestar atención por la cuestión social y realizar obras concretas a favor de la clase trabajadora, dio gran impulso a la formación de estas asociaciones, y en 1895 el Padre redentorista Federico Grote fundó en Buenos Aires la Federación de Círculos Obreros Católicos que contaba al año siguiente con representaciones a lo largo del país sumando 17 círculos con 4.000 afiliados. En 1902, existían 50 círculos con más de 13.000 afiliados y para 1913 habían crecido a 70 círculos con casi 24.000 afiliados (Zimmermann 1995: 53). En palabras del propio Grote, los C.O.O. serían "un medio para alejar a los obreros de los antros de perdición y ponerlos bajo el influjo saludable de la Iglesia". ${ }^{14}$

Los Círculos, según H. Spalding "se proponían ayudar al trabajador

13- Periódico La Nueva Era. Patagones- Viedma. Año XIV Nº 758, 26 de noviembre de 1916. p. 3 col. 1 y 2.

14- Citado en Auza 1962.

- Instituto de Estudios Socio-Históricos - Facultad de Ciencias Humanas - Universidad Nacional de La Pampa - 
por medio de obras sociales como socorros mutuos, y al mismo tiempo protegerlo contra la filosofía liberal de las otras agrupaciones obreras entonces en boga. En ellos se daba instrucción primaria para niños y enseñanza profesional a obreros. Las clases en el Círculo Central, según una fuente, Ilegaron a reunir 700 personas entre adultos y pupilos. También celebraron fiestas escolares, patrocinaban conferencias y suministraban locales donde los obreros podían pasar el domingo con amigos y practicar algún entretenimiento" (Spalding 1970: 500).

Si bien los Círculos Católicos de Obreros proponían una acción social a favor del obrero, igualmente admitían en su seno a personas de diversas categorías sociales y diversas profesiones. La acción social y las distintas formas de uso del tiempo libre sirvieron como modo de crear un repertorio de prácticas y conceptos que tendían a disciplinar el mundo del trabajo en términos distintos al de las sociedades de resistencia características de ese momento en el movimiento obrero (Reta. 2004:6).

En el caso del territorio muy tempranamente aparecen los primeros círculos en la capital Viedma en 1902 que tiene una estrecha relación con su similar de Carmen de Patagones fundado dos años después. Quienes estimulaban la conformación de estas organizaciones era la orden salesiana, la de mayor presencia en el territorio patagónico a partir de la ocupación militar de este territorio en 1879. La fuerte presencia de los salesianos en la denominada "cuestión social" quedó evidenciada en la organización y motorización de los grupos sindicales de origen católico en los que desempeñaban el rol de asesores espirituales.

Bajo el lema de "Dios, Patria y Trabajo" ambos Círculos desarrollan en estos primeros años del siglo XX una serie de acciones, dirigida a convertirse en ámbitos de encuentro y sociabilidad de los trabajadores además de inculcar en ellos, en el marco de una nación católica, el ideal de una patria que armonizara capital y trabajo.

En efecto, tanto en Viedma como en Carmen de Patagones, los Círculos Ilevan a cabo una intensa actividad relacionada con el mutualismo y el tiempo libre de sus asociados. En el primer caso, las acciones están dirigidas principalmente a cubrir las necesidades en materia de salud, tanto en el suministro de remedios como en asistencia médica; completando la actividad mutual con la ayuda pecuniaria en casos de fallecimiento. En este sentido debemos decir que ante la ausencia de cualquier tipo de sistema previsional, los círculos cumplieron un papel importante en el auxilio de los socios enfermos

.86. 
durante este periodo, y tal vez, esta acción mutual fuera uno de los atractivos para que los trabajadores católicos se asociaran.

En cuanto al tiempo libre, las actividades son muy variadas y van desde lo educativo con clases para niños y adultos, con la particularidad que algunos de los cursos para estos últimos, específicamente los italianos, se daban en su lengua de origen ${ }^{15}$, pasando por actividades recreativas, funciones teatrales y conferencias que abordaban temas como "La moral sin Dios", "El trabajo, la propiedad y el socialismo" y "Derechos y deberes del obrero", las que generalmente estaban dadas por los propios sacerdotes.

Y para llevar a cabo estas actividades se utiliza el tiempo libre que brindan los días feriados o no laborables y las fiestas de guardar. Dentro de éstas, sin lugar a dudas la que aparece como central en estos primeros años es la que se lleva a cabo en el mes de mayo, que es la conmemoración del patrocinio de San José, santo patrono de los C.O.C. de todo el país. Estos festejos religioso-sociales son celebrados conjuntamente por los Círculos Católicos de Viedma y Patagones quienes, junto a los sacerdotes que asesoran, preparan el programa de actividades con celosa puntillosidad. ${ }^{16}$

15- "Scuola Serale per gli operai

Soci del CIRCOLO CATOLICO

I Preti Salesiani di Patagones hanno deciso di pariré una scuola serale gratuita á benefizio dei soci del Circolo Catolico.

L'istruzione sará del tutto practica estendendosi particolarmente su queste materie. Lettura - Scrittura - Contabilitá doméstica - Religione".

Fuente: Periódico Flores del Campo Publicación Semanal. Viedma Año III Número extraordinario, mayo de 1905.

16- "Cúmplenos comunicar a Vd. Que el Directorio en su última sesión ordinaria, celebrada el día primero de mayo, ha resuelto poner en conocimiento de los socios, los actos a celebrarse para la gran solemnidad del 14 del corriente, fiesta del Patrocinio de San José, Patrono de nuestro Circulo.

\section{Solemne Triduo:}

En los días 11,12 y 13 a las 7 p.m. conferencia sobre temas de actualidad, a cargo del R. P. José Bettino. El día 14 a las 9 a.m. reunión de los socios en el local social. De allí saldrá el Círculo con su bandera, formando en columna, encabezado por la Banda del Colegio y si dirigirá al muelle para recibir al Círculo de Patagones. Por la tarde a las 3 Vísperas solemnes y Procesión alrededor de la Plaza.

Después de la Misa de las 10, los Círculos en corporación, con su bandera, precedidos por la Banda, se dirigirán a la quinta de los Padres Salesianos, para un modesto y fraternal almuerzo.

Alejandro Rossi

Secretario

Gracioso Zoni

Presidente

Nota: En las conferencias se desarrollaran los siguientes temas: La Religión y el obrero - El obrero y la familia. Jesucristo y el obrero. Fuente: Periódico Flores del Campo. Publicación Semanal. Viedma, 6 de mayo de 1905. Año III N 104. p. 819. 
Si para los socios de ambos círculos estos festejos adquieren una fuerte relevancia en el marco de incrementar la sociabilidad y la solidaridad interna, mucho más importante resulta este acontecimiento para la Iglesia y los sacerdotes de la misión salesiana que en definitiva son los que introducen la iniciativa y cooperan en la organización y realización de los festejos. Y esto queda cabalmente expresado en el número extraordinario que Flores del Campo, periódico editado por la Misión Salesiana en Río Negro, le dedica al mismo. La detallada y exultante crónica de los acontecimientos vividos ese día por los socios de ambos Círculos, que realiza la publicación mencionada, remata con algunas reflexiones finales del cronista que no duda en afirmar que "La fiesta celebrada el día del Patrocinio de San José ha sido un verdadero triunfo para los Círculos Católicos de Viedma y Patagones. Las proyecciones luminosas que arroja sobre el porvenir de estas regiones hacen concebir las más halagüeñas esperanzas de paz, felicidad, orden y progreso moral y material. ¡Adelante! ¡Siempre Adelante! He allí la palabra que brota espontánea en este momento de mi corazón. Hemos recorrido un buen camino, pero mucho más nos queda por andar, para llegar al desarrollo completo de la Acción Católica. ¡Adelante!, pues, siempre adelante, aumentando y estrechando más y más nuestras filas, oponiéndonos como fuertes murallas a la propagación de las ideas subversivas e impías"17.

La presencia de esta organización católica se mantuvo con altibajos en los años siguientes, y vuelve a tener una fuerte participación en el escenario regional a partir de los años veinte y en la década siguiente cuando surgen filiales de los Círculos de Obreros Católicos en distintas localidades del territorio rionegrino especialmente del Alto Valle ${ }^{18}$. Como en la primera época, la planificación del tiempo libre estaba casi exclusivamente ligada a la actividad desarrollada en los días festivos, pero ahora a las festividades del santo patrono y de las efemérides patrias se le agregaba también el $1^{\circ}$ de mayo. En este sentido, Ernesto Bohoslavsky señala que "la tradición festiva del Círculo de Obreros Católicos estaba ligada a los sectores nacionalistas e insistía en una definición mucho más organicista del pueblo trabajador, con una noción fuertemente impregnada de valoraciones católicas. Se consideraba al $1^{\circ}$ de

17- Periódico Flores del Campo . Publicación Semanal. Viedma Número extraordinario. Mayo de 1905. 18- La filial General Roca del Círculo de Obreros Católicos se fundó en 1931, en una reunión realizada en el colegio salesiano "Domingo Savio", convocada por el párroco Nazario Bórtoli. Fuente: Diario Río Negro. General Roca, 20 de agosto de 1931, p. 5.

.88 . 
mayo como un momento de descanso y de diversión para los trabajadores antes que como una instancia de reflexión y acción cívica" (Bohoslavsky 2003:62). De ahí la preferencia por la recreación más que por la conmemoración y como lo describe el periódico Río Negro, el día se iniciaba para los trabajadores con un breve tiempo formal de recordación en un acto público con ofrenda floral incluida, para transcurrir el resto de la jornada, con asado a la criolla, velada cinematográfica, bailes y juegos. ${ }^{19} \mathrm{El} 1^{\circ}$ de mayo era entendido entonces como un día de solaz y esparcimiento para los trabajadores católicos, aprovechando su condición de no laborable y no como lo concebían las organizaciones gremiales de izquierda, que lo consideraban una jornada de reflexión y de lucha.

En el marco de ampliar sus bases de sustentación en la sociedad, la Iglesia, a través de los Círculos Obreros, asumía en esta etapa un discurso anticomunista y antiliberal que armonizaba con el discurso y las políticas implementadas por los gobiernos que se suceden en este periodo de entreguerras, que tendían fundamentalmente a tratar de eliminar la conflictividad social.

\section{El Estado}

En la norpatagonia, en el período que nos ocupa existió una instancia del mundo del trabajo caracterizado por fuertes concentraciones obreras de carácter estatal. Se trataba de actividades que, como la explotación petrolífera o la construcción de obras hidráulicas, exigían la presencia de conglomerados más o menos numerosos de obreros en sitios relativamente aislados del resto de los Territorios.

En estas concentraciones, la nota distintiva, en lo referente al mundo laboral, está dada porque el Estado, que se presenta como empleador y regulador de las relaciones laborales y sociales, es quien maneja a discreción las formas de sociabilidad, las pautas culturales y la propia vida del trabajador y aún la de su propia familia, excediendo largamente el control sobre el proceso de trabajo incursionando activamente en el mundo de este fuera del ámbito laboral incluido el tiempo libre.

Por lo tanto la característica más significativa en estas concentraciones obreras es el peso empresarial estatal no solo en lo atinente a la organización

19- Periódico Río Negro. General Roca 2 de mayo de 1940. pp. 6 y 29 de abril de 1943, p. 5.

- Instituto de Estudios Socio-Históricos - Facultad de Ciencias Humanas - Universidad Nacional de La Pampa - 
del trabajo sino además en la estructuración de la vida cotidiana y de los espacios de socialización de los trabajadores.

En la práctica esto se verifica cuando el Estado, a través de los administradores en el caso de YPF o de los directores de las obras del Dique Neuquén, creó y controló una serie de instituciones que hacen a las redes de socialización de los trabajadores y las comunidades poblacionales que crecieron alrededor de la explotación en un caso y del emprendimiento hídrico por el otro: mutuales, cooperativas de consumo, clubes, bibliotecas, cinematógrafos.

De esta manera, como bien lo señala Daniel Cabral Márquez para el caso de YPF, pero que es perfectamente aplicable a las otras experiencias, "se instalaba un fuerte mecanismo de control social, que se expresaba en una cerrada disciplina laboral, y que trascendía al ámbito de la vida domestica, que desde la visión de la empresa no constituía en absoluto un espacio desvinculado de la esfera de su influencia" (Cabral Márquez 1992: 18).

En efecto, la capacidad de controlar y reglamentar iba más allá del mundo del trabajo y avanzaba en el ámbito de lo privado. En este aspecto son ilustrativas las memorias de los administradores como en el caso de Alberto Landoni administrador del yacimiento Plaza Huincul quien respecto a las actividades familiares de esparcimiento, nos informa que durante su gestión "por primera vez se permitió a los obreros concurrieran a los bailes con sus esposas e hijos" (Landoni 1986: 59).

Pero las prerrogativas que se atribuyen los administradores en cuanto a incidir en el tiempo libre de los trabajadores de la empresa no se detiene allí y alcanza niveles extremos cuando se adentra en el terreno de lo sexual. El mismo Landoni apunta, en el marco de su gestión como administrador, la puesta en marcha, bajo la autoridad de la empresa, de una casa de tolerancia, para uso de los empleados solteros; decisión tomada porque "los muchachos no veían ninguna mujer durante larguísimas temporadas, andaban con la mente en otro lado y cada vez rendían menos. También me inquietaban porque vivían de a dos" (Landoni, 1986, 61).

En términos generales este escenario se repite en el caso de las obras del Dique Neuquen, donde el poder del Director es prácticamente absoluto y abarca no sólo lo que tiene que ver con la obra en sí sino que además, su autoridad se extiende a otras facetas de la vida del campamento como la educación ya que cumplía las funciones de Encargado Escolar, designación ésta que provenía del Consejo Nacional de Educación y suponemos formaba

.90. 
parte de un acuerdo anterior entre el ministerio de Educación y el Ministerio de Obras Públicas. Según Catalina Simón "Por ese cargo cualquier decisión o necesidad de la escuela debía ser comunicada al director de las obras, por ejemplo, ampliación de la escuela, falta de muebles y útiles, ausentismo de los alumnos, etc." (Simón 1988: 5). El Encargado Escolar a su vez elevaba las notas al Inspector seccional de la escuela con asiento en Río Colorado, quien a su vez remitía las notas de repuestas a éste, quien la trasladaba a la escuela.

Como es de prever esta autoridad omnímoda generó una serie de altercados y conflictos jurisdiccionales por la falta de autonomía de las diversas reparticiones públicas existentes en el campamento o ligadas a él. Al respecto el periódico Río Negro, a principios de 1921, hacía el siguiente comentario:

"Ha llegado hasta nosotros los ecos de conflictos latentes que existen en el perímetro urbano enclavado dentro de la jurisdicción a cargo de la dirección de las obras que se construyen en Cordero.

Trátase de un viejo asunto, que renace de tanto en tanto, a causa de fallas fundamentales que anulan la autonomía de las diversas reparticiones públicas.

Se nos dice que recientemente un grupo de obreros, sin tener para nada en cuenta a la directora de la escuela penetró en el local haciendo excavaciones y arruinando plantíos, porque obedecían las órdenes emanadas de la dirección.

También parece que los servicios ferroviarios están sujetos a la fiscalización de la dirección. Recordando casos anteriores, hasta la policía y el correo funcionaron con el visto bueno de un sistema creado exclusivamente para servir los intereses del Estado en obras para endicar el Neuquen y regadío de gran aliento.

Yendo, entonces, al fondo de la delicada cuestión, hemos de reconocer que la culpa no corresponde al ministerio de Obras Públicas. No encontró resistencia e hizo del campamento una fuerza absorbente, en manos de la Dirección de las Obras, que anuló la natural fuerza expansiva tendiente a crear una zona urbana regida por leyes y reglamentos propios de todos los pueblos del territorio" ${ }^{\prime 20}$.

Dentro de este marco, el caso de la creación y posterior funcionamiento de la Biblioteca Popular y Museo "Florentino Ameghino", demuestra con claridad las formas que el Estado, en este caso representado por el Adminis-

20- Diario Río Negro, General Roca, Año IX, N 479 17/03/1921, p. 3 col. 2. 
trador de las obras del Dique Neuquén, practica una política de control sobre los trabajadores que se extiende más allá del mundo del trabajo y avanza en el tiempo libre del trabajador.

En efecto, hacia 1920 y por iniciativa de la directora de la escuela $\mathrm{N}^{\circ}$ 37 que como hemos visto funciona en las inmediaciones del campamento, se funda la que sería la primera biblioteca pública en territorio rionegrino.

Como era de esperar la primera comisión directiva quedará encabezada por el Ing. Lépori director de las obras como presidente y la Sra. Manuela M. de Noriega, directora de la escuela como secretaria, mientras que los jefes de estación, de almacenes, de correos y trabajadores calificados del campamento completan los cargos restantes.

Al leer los fundamentos y objetivos expuestos en el libro de Actas de esta institución queda claramente expresada, más allá del objetivo primario de ser un ámbito de cultura y educación, la firme voluntad de parte de las autoridades de convertir a esta biblioteca en un instrumento que coadyuve al proceso de "argentinización" y un vehículo eficaz para la reproducción del orden social vigente, ya que los objetivos transcriptos sostienen enfáticamente la necesidad de "disponer de una sección infantil donde el ciudadano de mañana encuentre y asimile los conocimientos que no abarca la escuela primaria, contribuyendo a arraigar en su alma el sacro amor a la Patria, el respeto a las instituciones y la estabilidad social que en ella le inculcaron"21.

Asimismo, y con el mismo espíritu que el Gral. Moscón defendiera en Y.P.F., afirman que: "como argentinos habitantes de su suelo debemos decidida protección a las industrias nacionales por ser ellas la columna en que descansa el progreso y bienestar de la Patria". 22

Como era de esperar, la red de vinculaciones de la Biblioteca, integrada por instituciones oficiales y empresariales, así como editoriales, excluye las de carácter obrero o similar, mientras que su fichero se compone de títulos que tienen que ver con obras de carácter pasatista - novelas de aventura o del género romántico - e historias nacionales, grandes biografías, manuales técnicos y revistas deportivas, con la obvia exclusión de publicaciones de ideologías obreras críticas del orden social vigente.

Respecto a otras instituciones, como el Radio Club y el Cinematógrafo, ambos de carácter mutual, el análisis de la composición de sus respectivas

21- Libro de Actas de la Biblioteca Popular y Museo "Florentino Ameghino", p. 1.

22- Libro de Actas de la Biblioteca Popular y Museo "Florentino Ameghino", p. 1.

.92. 
comisiones directivas revela también la fuerte incidencia de la Administración de las obras en su funcionamiento.

Las actividades del tiempo libre se completaban en la faz deportiva, para estos trabajadores contratados por el Estado, con el funcionamiento del Club Atlético Dique Neuquén y Lago Pellegrini, cuya principal disciplina era la práctica del fútbol y donde también se hacía sentir la presencia estatal.

\section{Algunas reflexiones finales}

En consonancia con lo que sucedía en otras regiones del país, también en la norpatagonia resulta evidente que, en la medida que se iba reduciendo la jornada laboral y aumentaba el tiempo libre de los trabajadores, éste se convertía en un terreno fértil para que una serie de instituciones como las organizaciones políticas y sindicales, la iglesia y el propio Estado, intentaran a través de diversas estrategias, tales como la recreación, las actividades culturales o las prácticas deportivas, imponer sus propios contenidos ideológicos. Incluso en muchos casos la aplicación de estas acciones dieron lugar a verdaderas batallas ideológicas sobre las consecuencias positivas o negativas que las mismas tenían sobre la clase trabajadora, como en las actividades deportivas impulsadas por socialistas y comunistas que reciben un fuerte cuestionamiento e impugnación de parte de anarquistas y sindicalistas.

Pero también el sesgo ideológico está presente en el tipo de lecturas que el Estado impone a los trabajadores bajo su dependencia, o en las temáticas de las conferencias dictadas en el seno de los Círculos de Obreros Católicos.

Es decir, que el interés de estas instituciones y del propio Estado iba más allá del objetivo inmediato de garantizar para los trabajadores un mejor aprovechamiento del tiempo libre, haciendo más placentero los momentos dedicado al ocio. Por el contrario estas acciones formaban parte de una estrategia más amplia que se combinaba y complementaba con las que paralelamente se desarrollaban en el mundo del trabajo y que en el caso de las organizaciones políticas y sindicales pasaban por propagandizar las ideas que sirvieran para concientizar a los trabajadores en la lucha de clases, en la construcción de una nueva sociedad y adicionalmente fortalecer la estructura sindical. De la Iglesia en una clara intención de disciplinar el mundo del trabajo, de cristianizarlo, instruyendo a los obreros católicos, a través de las encíclicas, en un mundo de relaciones armónicas entre capital y trabajo y 
de rechazo a la alteración del orden social vigente y a las formas de participación obrera características de las sociedades de resistencia. Y por último el Estado cuyo objetivo principal era la de controlar, regular y disciplinar la mano de obra empleada en los emprendimientos estatales.

Finalmente, digamos que estas prácticas, lejos de desaparecer en la etapa posterior, se reforzaron e institucionalizaron con la llegada del peronismo, aunque en el caso de las organizaciones sindicales y el propio Estado, con otras miradas pero con el mismo interés de antaño; es decir, incidir en su planificación y consumo.

\section{Bibliografía}

\section{Fuentes}

Archivo Histórico de la Provincia de Río Negro Archivo Histórico de la Provincia de Neuquen. Archivo de Y.P.F. Plaza Huincul Archivo de Agua y Energía (Barda del Medio Río Negro)

Biblioteca Popular y Museo "Florentino Ameghino". Libro de Actas. Congreso Nacional. Cámara de Diputados. Diario de Sesiones. Periódico Río Negro, General Roca 1912-1945.

Periódico Flores del Campo, Viedma 1903 -1945

Periódico La Nueva Era, Patagones-Viedma 1915-1945

\section{Libros y artículos}

- AUZA, Néstor (1962) Los católicos argentinos. Su experiencia política y social, Buenos Aires, Diagrama.

- BARRANCOS, Dora (1990) Anarquismo, educación y costumbres en la Argentina de principios de siglo, Buenos Aires, Contrapunto.

- BOHOSLAVSKY, Ernesto (2003) "El nacionalismo norpatagónico en los orígenes del peronismo 1930-1943", en: Rafart, G. y Mases, E. El peronismo desde los territorios a la nación. Su historia en Neuquen y Río Negro (1943-1958), Neuquen, Educo, pp. 45-76.

- CABRAL MÁRQUEZ, Daniel (1992) Las políticas sociales de YPF y su impacto en la formación de la "comunidad petrolera" estatal. El caso del yacimiento Comodoro Rivadavia. Comodoro Rivadavia, policopiado.

- CHIARANTE, Pedro (1976) Memorias. Buenos Aires y el movimiento obrero desde principio de siglo, Buenos Aires, Fundamentos.

.94. 
- FALCÓN, Ricardo (1986) El mundo del trabajo urbano (1890-1914), Buenos Aires, CEAL.

- GONZÁLEZ LEANDRI, Ricardo (2001) "La nueva identidad de los sectores populares", en: A. Cattaruzza, Crisis Económica, avance del Estado e incertidumbre política (1930-1943). Nueva Historia Argentina. Buenos Aires, Sudamericana, Tomo 7, Capítulo V. pp. 201-237.

- HOBSBAWM, Eric (1991) "El trabajo en la gran ciudad", en: Entrepasados. Revista de Historia, Buenos Aires, Año I N 1. pp. 79-92.

- LANDONI, Alberto (1986) Cuatro gotas de petróleo, Buenos Aires, Huges Tool Co.

- MASES, Enrique y otros (1994) El mundo del trabajo: Neuquén 18841930. Neuquén, GEHiSo.

- MATEU, Cristina (1998) "Política e Ideología de la Federación Deportiva Obrera 1924-1929", en: P. ALABARCES, R. DI GIANO y J FRYDENBERG (compiladores), Deporte y Sociedad, Buenos Aires, EUDEBA, pp. 67-86.

- RETA, María (2004) Sectores populares e Iglesia o como disciplinar el mundo del trabajo. El Círculo Católico de Obreros en Gral. Roca (19311943), Ponencia presentada en las 1 ras. Jornadas de Investigación en Ciencias Sociales. Facultad de Derecho y Ciencias Sociales. Universidad Nacional del Comahue. 4 y 5 de noviembre de 2004. Mesa: Historia y Filosofía.

- REYNOSO, Roberto (compilador) (1985) "Bandera proletaria": selección de textos (1922-1930), Buenos Aires, CEAL, Biblioteca Política Argentina $N^{\circ} 106$.

- ROMERO Luis A. (1995) "Participación política y democracia 18801984", en: L. H. Gutiérrez y L. A. Romero, Sectores Populares. Cultura y Política. Buenos Aires en la entreguerra, Buenos Aires, Sudamericana, pp. 107-152.

- SIMON, Catalina (1988) "El Dique". Los cinco primeros años de la biblioteca popular y museo "Florentino Ameghino" (1920-1925), Barda del Medio, mecanografiado.

- SPALDING, Hobart (1970) La clase trabajadora Argentina. (Documentos para su historia - 1890-1912), Buenos Aires, Galerna.

- STEDMAN JONES, Gareth (1987) "Cultura y política obreras en Londres, 1870-1900: notas sobre la reconstrucción de una clase obrera", en: Revista En Teoría. Barcelona, 1987 N 8/9, pp. 32-98.

- SURIANO, Juan (2001) Anarquistas. Cultura y política libertaria en Buenos Aires 1890-1910, Buenos Aires, Manantial. 
- ZIMMERMANN, Eduardo (1995) Los Liberales Reformistas. La cuestión social en la Argentina 1890-1916. Buenos Aires, Sudamericana-Universidad de San Andrés.

\section{Resumen}

Este artículo estudia el papel desempeñado por las organizaciones políticas y sindicales, la Iglesia y el propio Estado en el tiempo libre de los trabajadores en la norpatagonia, en el período de tiempo que va desde los inicios del siglo XX hasta el advenimiento del peronismo. En el mismo, se describen las diferentes estrategias que cada una de estas instituciones puso en práctica, en función de la planificación y consumo del ocio de los trabajadores, y se analizan los intereses de cada una de ellas, que iban más allá de garantizar para los trabajadores un mejor aprovechamiento del tiempo libre. Por el contrario, las acciones puestas en prácticas formaban parte de una estrategia más amplia que se combinaba y complementaba con las que paralelamente se desarrollaban en el mundo del trabajo. En el caso de las organizaciones políticas y sindicales pasaban por propagandizar las ideas que sirvieran para concientizar a los trabajadores en la lucha de clases, en la construcción de una nueva sociedad y adicionalmente fortalecer la estructura sindical. En el caso de la Iglesia, las acciones se enfocaban hacia una clara intención de disciplinar el mundo del trabajo, de cristianizarlo, instruyendo a los obreros católicos, a través de las encíclicas, en un mundo de relaciones armónicas entre capital y trabajo y de rechazo a la alteración del orden social vigente y a las formas de participación obrera características de las sociedades de resistencia. Por último, en las acciones el principal objetivo era la de controlar, regular y disciplinar esta mano de obra.

Palabras claves: Tiempo Libre, trabajadores, sindicatos, Iglesia, Estado.

\section{The workers' leisure time in Northern Patagonia. From political cul- ture, recreational and sports practices to social discipline, 1900-1945 Summary}

This paper studies the role of political organizations, the church, the state and labor unions in the leisure time of the workers in Northern Patagonia from the beginning of the $19^{\text {th }}$ century, up to the rise of peronismo. We discuss the strategies put into practice by such institutions, as related with

.96. 
the planning and consumption of their spare time. We also analyze each institution's interests, which went far beyond making themselves sure that the workers' could take better advantage of their leisure time. Far from that, these actors' actions were part of a wider strategy that could be combined with the one developed within the workers' world. In the case of political and labor unions' organizations, such actions were related with the spreading of ideas that could be useful to reinforce consciousness for class struggle, to build a new society and aditionally, to strengthen trade union structures. The actions of the church, on the other hand, were oriented towards disciplining the working world, christianizing it, and indoctrinating catholic workers in a world of armonic relations between capital and labor and teaching them to reject alterations of the status quo and the workers' ways of participation typical of resistance societies. Finally, actions performed by the State attempted to control, regulate and discipline such workers.

Key words: Leisure time, workers, trade unions, Church, State.

Recibido 16/06/05, aceptado 31/08/05. 